\title{
Incidence of Sub-Clinical Prostatic Disease at Autopsy in the University College Hospital, Ibadan
}

\author{
Chukwudi Okani, Effiong Akang, Olufemi Ogunbiyi" \\ Department of Pathology, University College Hospital, Ibadan, Nigeria \\ Email: * fogunbiyi@comui.edu.ng
}

Received December 28, 2012; revised January 30, 2013; accepted February 8, 2013

Copyright (C) 2013 Chukwudi Okani et al. This is an open access article distributed under the Creative Commons Attribution License, which permits unrestricted use, distribution, and reproduction in any medium, provided the original work is properly cited.

\begin{abstract}
This prospective study was undertaken to ascertain the incidence, histology and pathological features of different types of asymptomatic or sub clinical prostatic diseases. Prostate glands were obtained from 79 consecutive adult males aged 30 years and above who died from non-prostate related diseases at the University College Hospital Ibadan over an eighteen months period. The glands were weighed and fixed in $10 \%$ neutral buffered formalin. The sampling method of the prostate gland described by Vainer et al. (2011) was employed in this study. Paraffin-embedded sections were stained with haematoxylin and eosin and were systematically examined for focal prostate disease. The patients' ages ranged from 30 to 86 years. The most common lesions were nodular hyperplasia $(81 \%)$, followed by adenocarcinoma $(6.3 \%)$. Three cases $(3.8 \%)$ had schistosomiasis. Adenocarcinoma and nodular hyperplasia occurred in relatively older patients than those with normal glands or chronic prostatitis/schistosomiasis $(p=0.05)$. There was an increase in weight of the prostate with age $(\mathrm{p}<0.001)$ and normal prostate glands weighed significantly less than diseased glands $(\mathrm{p}=$ 0.02). Focal prostatic atrophy was observed in $24.1 \%$ and metaplastic changes were observed in eight (10.1\%) of the cases. Prostatic intraepithelial neoplasia (PIN) was not seen in any case, not even amongst the adenocarcinomas. The low frequency of prostatic adenocarcinoma and the absence of high grade prostatic intraepithelial neoplasia in this study despite the observation of increasing number of prostatic carcinoma requires further investigation.
\end{abstract}

Keywords: Prostate; Adenocarcinoma; Schistosomiasis; Prostatitis; Ibadan

\section{Introduction}

A wide range of neoplastic and non-neoplastic diseases may be associated with the prostate gland. Whereas other non-neoplastic prostatic diseases are clinically important because of the negative health and social impact they may have on the patient, cancer of the prostate is the major health challenge, particularly in middle-aged men [1]. Most studies demonstrate that African-American men are first seen with a higher stage of disease than whites and thus have an overall greater mortality rate from prostate cancer $[2,3]$. However, some reports show that African-American and white men have equivalent survival figures stage for stage [4].

Prostatic carcinoma is an emerging health concern among middle-aged Black African males and recent data from the Ibadan Cancer Registry suggest a rising incidence in reported cases [4]. Whereas there are numerous post-mortem studies that have documented the frequency

${ }^{*}$ Corresponding author. of incidental prostatic carcinoma in Caucasians [5], there is a paucity of similar studies from Nigeria and other parts of Africa [3,5]. It stands to reason that if truly there is a high incidence of any cancerous lesion in a given population, there would be in addition a corresponding high incidence of the pre-neoplastic lesions amongst the asymptomatic population. A well-established prostatic precancerous lesion is high grade prostatic intraepithelial neoplasia (HGPIN). We therefore embarked on this research to determine the frequency of pre-neoplastic prostatic cancer, sub-clinical prostate cancer and other forms of non-neoplastic (inflammatory or hyperplastic lesions) asymptomatic prostatic diseases in adult male patients at autopsy in Ibadan, South-West Nigeria.

Prostatic diseases can be broadly classified into three; the non-neoplastic diseases, neoplastic prostatic diseases, and miscellaneous conditions. The non-neoplastic prostatic diseases include: inflammation and infection, prostatic atrophy, prostatic metaplasia, benign prostatic hyperplasia and prostatic atypical adenomatous hyperplasia 
(adenosis). Prostatic atrophy is morphologically classified into: diffuse atrophy and focal atrophy. Neoplastic diseases of the prostate include: adenocarcinoma and the unusual primary malignant tumours [6]. Miscellaneous conditions include prostatic atrophy, which is morphologically classified into: diffuse atrophy and focal atrophy.

The frequency of benign prostatic hyperplasia is extremely low in men younger than 40 years, after which its development increases steadily. Nodular hyperplasia is the most common urologic disorder in men and its frequency rises progressively with age, reaching $90 \%$ by the eighth decade. Nodular hyperplasia and prostate cancer cause significant morbidity and mortality and especially so in African men [7].

Partial atrophy is the most frequent mimicker of adenocarcinoma on needle biopsies. It has been suggested that there is a possible link between prostatic atrophy and high-grade prostatic intraepithelial neoplasia (HGPIN) and/or carcinoma. However, the association between partial atrophy and HGPIN and carcinoma remains controversial $[8,9]$.

Chronic inflammatory processes of the prostate may follow clinical episodes of acute prostatitis, or may develop insidiously, without previous clinical episodes of acute inflammation. Chronic prostatitis is as common in Nigeria as it is in the developed world [10-12].

Non-infectious chronic prostatitis may occur in the absence of any pathogen.

Prostatic intraepithelial neoplasia (PIN) is known to coexist with impalpable carcinomas. Frequency rate and pathological features of both entities show significant variations in the medical literature [13-16].

\section{Methodology}

Over an 18-month-period of study we examined the prostate glands from 79 consecutive post-mortem cases of adult male patients who died of non-prostate related illnesses. In individual cases, the gland was removed intact, cleaned of any non-prostate tissue, weighed and fixed in $10 \%$ neutral buffered formalin. Partial embedding method was employed as described by Vainer et al. The glands were sectioned into horizontal slices. Apex and basis were cut sagittally, and some of the remaining slices were embedded in quadrants. The paraffin-embedded sections were stained with haematoxylin and eosin and were systematically examined for prostate disease [17].

\section{Results}

\subsection{Study Population}

All of the patients were black Africans who resided in Ibadan, South-West Nigeria and its environs. The most common causes of death were cardiac diseases $(38 \%)$, violent deaths (24.4\%) and neoplastic diseases (10.1\%).

\subsection{Age Distribution}

The ages of the patients ranged from 30 to 86 years, with a peak during the 50 - 59 years age group (Figure 1). The mean age of the patients was $50.4 \pm 13.9$ years.

\subsection{Distribution of Prostate Weights}

The weights of the prostate glands ranged from 10 to 100 $\mathrm{g}$ with a mean of $30.9 \pm 17.0 \mathrm{~g}$. There was a significant increase in the mean weight of the prostate gland with increasing age. The mean age of patients with prostate glands weighing $30 \mathrm{~g}$ or less $(44.1 \pm 11.9$ years $)$ was significantly less than that of patients with prostate glands weighing greater than $30 \mathrm{~g}(60.6 \pm 10.5$ years $), \mathrm{t}=6.2, \mathrm{df}$ $=77, \mathrm{p}<0.001$ with a maximum mean weight in the ninth decade of life, as shown in Figure 2, $(\mathrm{F}=12.8, \mathrm{p}<$ $0.001)$.

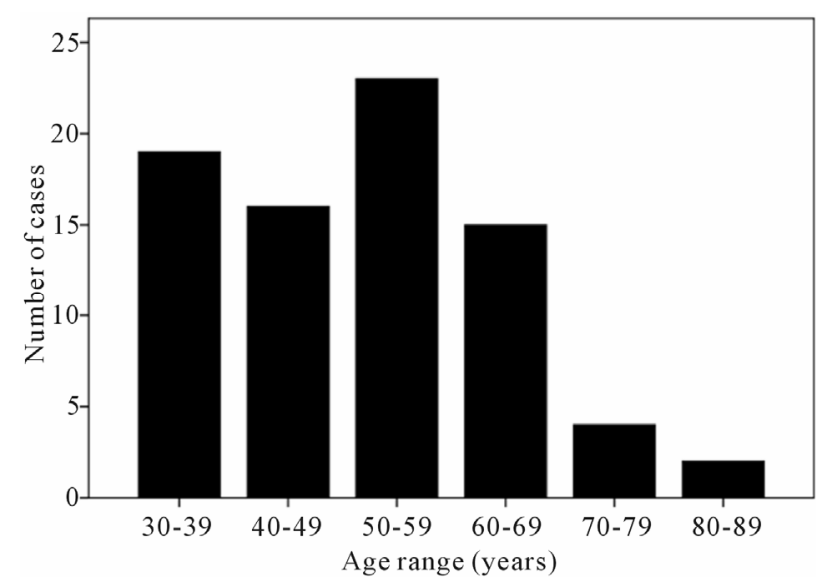

Figure 1. Age distribution of patients examined.

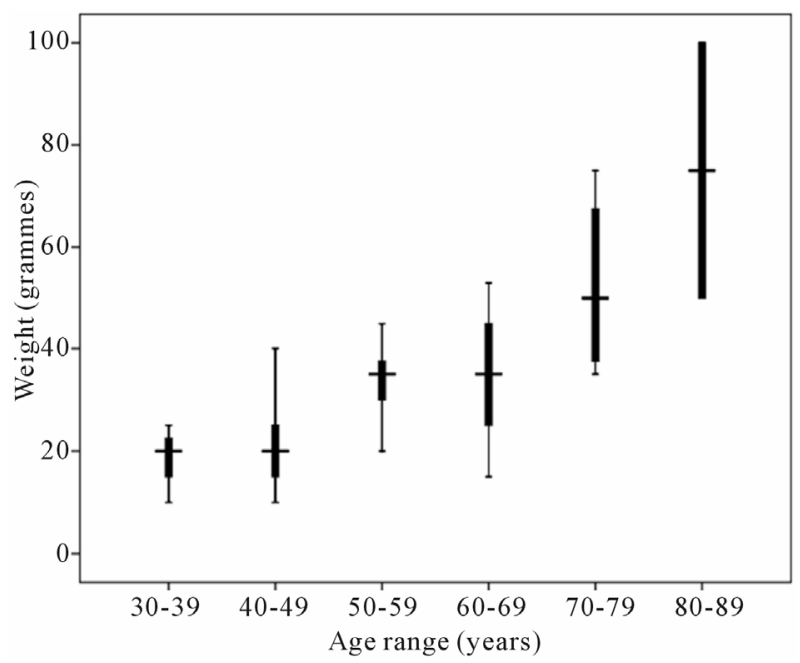

Figure 2. Distribution of mean weight of prostate gland with age group. 


\subsection{Types of Prostate Lesions}

The most common lesion identified was nodular hyperplasia (Figure 3), accounting for 64 (81\%) of the cases. Five patients $(6.3 \%)$ had incidental adenocarcinoma (Figure 4), one patient (1.3\%) had isolated chronic prostatitis and three patients $(3.8 \%)$ had schistosomiasis (Figure 5). These three were associated with adenocar

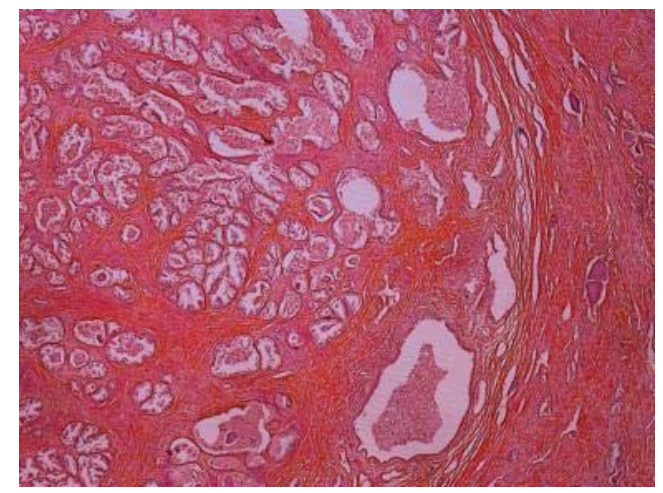

Figure 3. Photomicrograph showing nodular hyperplasia in prostate of a 30-year-old man who died of perforated peptic ulcer disease (Haematoxylin and eosin).

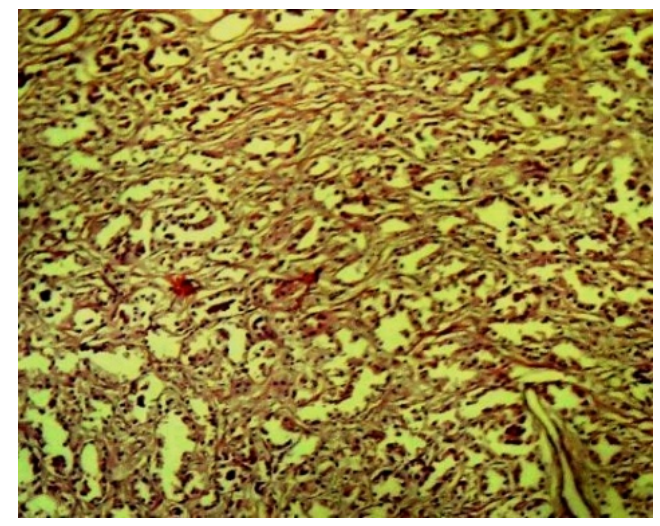

Figure 4. Photomicrograph showing Gleason grade 2 score 4 adenocarcinoma in the prostate (Haematoxylin and eo$\operatorname{sin).}$

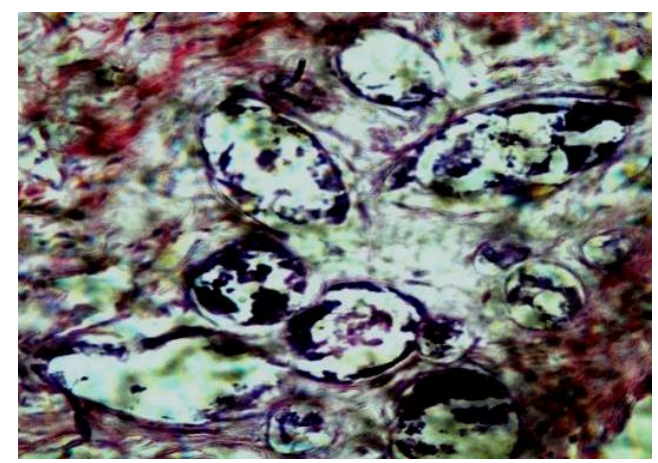

Figure 5. Photomicrograph showing calcified ova of Schistosoma haematobium in the prostate of a 30-year-old man (Haematoxylin and eosin, $\times 400)$. cinoma and with nodular hyperplasia in one case each, and schistosomiasis was isolated in the third case. Eight $(10.1 \%)$ of the patients in the present study had normal prostate glands. In all, about $90 \%$ of the study population had some disease in the prostate gland. Table 1 summarizes the causes of death with the corresponding Gleason's grades of prostatic adenocarcinoma amongst the five cases that had incidental prostatic adenocarcinoma.

\section{Discussion}

A total of 79 prostate glands from adult males aged 30 years and above who died of non-prostate related diseases were analysed. Due to a global decline in autopsy rate and improved diagnostic methods in this modern era, we were unable to attain high numbers of cases as in the first autopsy study of prostate disease performed by Rich in the early 1930s to determine the frequency of occurrence of occult carcinoma of the prostate at the Johns Hopkins Hospital, USA, which included 292 cases [18].

High frequencies of incidental carcinoma of $18.8 \%$ and $14 \%$ have been recorded among Caucasians by Stamatiou et al. from Greece and Rich from the USA, respectively $[19,20]$. Soos from Hungary recorded a $38.8 \%$ prevalence of incidental prostatic adenocarcinoma amongst 139 patients seen at autopsy [21]. There appears to be a higher number of subclinical prostate cancer cases in Caucasians when compared with $6.3 \%$ of incidental adenocarcinoma recorded in this study. Most Caucasian studies recruited men aged 40 years and above, and this could probably explain the reason why the frequency appears higher since prostatic adenocarcinoma incidence is known to increase with age.

The peak occurrence of adenocarcinoma in this study was in the sixth decade of life, with a subsequent gradual decline. By contrast, Franks in 1954 reported a peak occurrence of prostate cancer among Caucasians in the eighth decade of life [22].

Two cases of the adenocarcinoma showed Gleason score 4 and 5 each while the remaining 3 cases had Gleason score 6 each (Table 1).

Table 1. Summary of clinical and pathological bio data of the five patients with incidental adenocarcinoma of prostate.

\begin{tabular}{ccc}
\hline Age (years) & Anatomical diagnosis & Gleason's grade and score \\
\hline 36 & Craniopharyngioma & Grade 3 score 6 \\
50 & $\begin{array}{c}\text { Road traffic accident with } \\
\text { severe head injury }\end{array}$ & Grade 3 score 6 \\
60 & $\begin{array}{r}\text { Hypertensive intracerebral } \\
\text { haemorrhage }\end{array}$ & Grade 3 score 6 \\
63 & Miliary tuberculosis & Grade 2 score 4 \\
73 & Hypertensive heart disease & Grade 3 score 5 \\
\hline
\end{tabular}


Nodular hyperplasia was observed in $64(81 \%)$ cases. $55.7 \%$ of those who were aged 50 and above showed evidence of nodular hyperplasia while only $17.4 \%$ of those between 30 and 49 years showed nodular hyperplasia. The findings are also comparable with the findings by Berry et al. in 1984 where he summarized five autopsy series addressing the prevalence of histological nodular hyperplasia according to age, and they noted that nodular hyperplasia was never observed in men less than 30 years of age while about $50 \%$ of men in the sixth decade of life had histological nodular hyperplasia of the prostate [23]. In the present study, $91.3 \%$ and $100 \%$ of men in the sixth and ninth decades of life had nodular hyperplasia.

Several Caucasian studies show that prostatic carcinoma discovered in asymptomatic patients at autopsy are usually well differentiated adenocarcinomas with a Gleason score of between 2 and 4, and only very few are poorly differentiated with Gleason score of 6 to $7[18$, 21-25]. In the present study, prostatic intraepithelial neoplasia (PIN) was not recorded. By contrast to these observations, Sakr et al. from the United States found that as many as $34 \%$ of men in their $40 \mathrm{~s}$ exhibited high grade prostatic intraepithelial neoplasia (HGPIN) [26]. An autopsy study by Sakr and colleagues revealed that HGPIN occurred in $57 \%$ of African American men and $33 \%$ of Caucasian American men [27]. In an autopsy series from Hungary it was noted that in the age group 81 - 95 years, $60 \%$ of men had HGPIN [21]. The absence of HGPIN and the relatively low frequency of incidental carcinoma in the data obtained in this study apparently contrasts with the documentation of a high prevalence of prostatic adenocarcinoma in the American black population [2832]. HGPIN is an important precursor lesion of prostate cancer [30], although some authors still believe that consensus have not been reached as to the risk of cancer following the diagnosis of HGPIN [1]. Therefore, the absence of HGPIN in this study is surprising, since prostate cancer is the most common malignancy in Nigerian males. Vainer et al. and Gill et al. demonstrated that partial embedding of radical prostatectomy specimen loses minor information as regards the grading and staging of prostatic tumour. They did not discuss the context of absence or presence of HGPIN using this technique. They noted that this information loss may affect the planning of post-surgical treatment and follow-up [17, 33]. In addition, Bostwick and Meiers documented that complete sampling was found to give a significant increase in positive surgical margins. They also noted that the presence and extent of staging of adenocarcinoma were directly related to the number of tissue blocks submitted for histologic examination [34]. In this study, partial embedding sampling method was used and a complete absence HGPIN in this study may not be uncon- nected with the sampling methods used.

None of the carcinomas in this study showed evidence of perineural invasion or distant metastasis in agreement with other studies done elsewhere [21-25,35]. Chronic prostatitis was discovered in association with other lesions in this study. Only one patient had isolated chronic prostatitis representing $1.3 \%$ of the 79 men. There were three $(3.8 \%)$ cases of schistosomiasis of the prostate without concomitant bladder infestation, in this study. However, in a study of 499 autopsy cases by Edington et al. in Ibadan in 1975 (about 37 years ago), S. haematobium infection was seen in 98 cases $(19.6 \%)$, out of which the prostate gland was involved in $8.16 \%$ of cases, histologically [36]. This reduced incidence might reflect a change in disease trend over the past 37 years due to improved health care and disease awareness. In another autopsy study performed by Gelfand M. et al. on 300 males in Rhodesia (now Zimbabwe) prostatic schistosomiasis was found in $20.7 \%$ of cases [22].These findings were rather high compared to the $3.8 \%$ incidence found in this study. More cases of schistosomiasis may have been found in this study if potassium hydroxide were used to digest the prostate gland, as was done in the two earlier African studies cited [37].

One interesting case of prostatic schistosomiasis in the present study also had concomitant prostatic adenocarcinoma and miliary tuberculosis. Several authors have reported anecdotal associations between prostatic adenocarcinoma and schistosomiasis of the prostate gland [24, 38-41]. Cohen et al. reported on 3 patients aged from 27 to 29 years who lived in a schistosomiasis endemic rural community in South Africa and presented with elevated serum prostatic specific antigen (PSA), intense infestation of the prostate gland with Schistosoma haematobium and advanced prostatic adenocarcinoma [38]. Godec et al. documented a case of carcinoma of the prostate gland occurring synchronously with S. Mansoni in a 49 years old Puerto Rican born man living in the United States for 25 years [39]. A 55 year old man of Ghanaian extraction who had resided in Canada for 19 years was reported by Ma and Srigley of having prostate carcinoma concurrently with schistosomiasis of the seminal vesicle though the schistosomiasis did not involve the prostate gland [40]. Basílio-de-Oliveira C.A. et al. reported a case of 68 years old Brazilian man with $\mathrm{S}$. mansoni prostatic infestation occurring with adenocarcinoma of the prostate [41]. Elevated levels of urinary beta glucuronidase have been reported with patients with vesical schistosomiasis, which accounts for the increased occurrence of bladder cancer in these cases. However, the relationship between schistosomiasis and prostatic adenocarcinoma is not clear [40]. Some epidemiological, genetic and cell biological studies suggest a relationship between inflammation and prostatic carcinoma. The class glutathione S-transferase 
(GSTP1) gene encodes an enzyme that acts as a carcinogen detoxifier. GSTP1 is believed to be a "caretaker" gene, because it actively protects the cell from oxidative genome damage mediated by carcinogens and electrophilic compounds. Cells lacking GSTP1 accumulate oxidized DNA bases in response to oxidative stress, a situation that may occur at sites of inflammation $[42,43]$.

There was an incidental case of craniopharyngioma in one of the patients with prostatic adenocarcinoma. Activation of HER1 has been demonstrated by polymerase chain reaction and Western Blotting in cases of craniopharyngioma [44]. The EGFR related gene products HER2 and HER4 have been linked to prostate carcinogenesis. While increased HER2 appears to confer reduced survival, HER4 over expression is associated with increased survival [45]. It is not clear whether all these relationships will explain the simultaneous occurrence of prostatic carcinoma and craniopharyngioma. However, the occurrence of two distinct lesions at a young age makes one wonder if in fact there might be a common genetic link between the two lesions. Further studies are required to delineate this.

In the present study, focal prostatic atrophy was observed in $24.1 \%$ of the cases. The peak frequency was in the seventh decade of life. It has been observed that prostatic atrophy commences during the 5 th decade, with continued progression of the process into the 8th decade $[8,46]$. It has been suggested that there is a possible link between prostatic atrophy, high-grade prostatic intraepithelial neoplasia (HGPIN) and/or carcinoma [9]. However, the association between partial atrophy and HGPIN and carcinoma remains controversial [9].

Metaplastic changes were observed in eight $(10.1 \%)$ of the 79 patients. Four $(50 \%)$ of these cases had evidence of chronic inflammatory cell infiltration, mainly lymphocytes. One of the cases with lymphocytic infiltration in addition harboured numerous calcified ova of Schistosoma haematobium. These finding are in agreement with the documentations in the literature that prostatic metaplastic changes may be associated with trauma, inflammatory lesions of the prostate or evidence of hormonal therapy [6].

\section{Conclusions}

In conclusion, this study has highlighted several important findings in the prostates of asymptomatic Nigerian adult males. There was a striking observation of a low frequency of incidental carcinomas and high-grade prostatic intraepithelial neoplasia in this and a similar study in Lagos.

Schistosomiasis was seen in $3(3.8 \%)$ of prostates. Each of the cases was associated with adenocarcinoma and with nodular hyperplasia while a case had neither adenocarcinoma nor nodular hyperplasia association.
Limitations to identifying HGPIN have been addressed by the use of immunohistochemistry markers p63, 34ßE12 as well as alpha-methyl acyl coA racemase (AMACR) in some situations. The use of these markers in future studies will help validate the frequency seen in this study. This important observation suggests that progression through PIN to carcinoma is not common among Nigerian Africans and supports the current view of aggressive disease in this population.

\section{REFERENCES}

[1] J. I. Epstein, “Adenocarcinoma of the Prostate,” In: Sternberg's Diagnostic Surgical Pathology, 5th Edition, Lippincott Williams \& Wilkins, New York, 2004, Chapter 45.

[2] M. A. Jackson, J. Kovi, M. Y. Heshmat, T. A. Ogunmuyiwa, G. W. Jones, A. O. Williams, et al., "Characterization of Prostatic Carcinoma among Blacks: A Comparison between a Low-Incidence Area, Ibadan, Nigeria, and a High-Incidence Area, Washington, DC," Cancer Chemother Rep Prostate, 1980, pp. 185-205.

[3] M. A. Jackson, B. S. Ahluwalia, J. Herson, M. Y. Heshmat, A. G. Jackson, G. W. Jones, et al., "Characterization of Prostatic Carcinoma among Blacks: A Continuation Report," Cancer Treat Rep, Vol. 61, No. 2, 1977, pp. 167-172.

[4] J. O. Ogunbiyi, "Cancer Incidence and Top Ten Cancers In Eleven Local Government Areas In Ibadan, Nigeria And Its Environs, 2004-2008," Ibadan Cancer Registry, 2010.

[5] J. Kovi, "Cancer of the Prostate and Aging: An Autopsy Study in Black Men from Washington, DC, and Selected African Cities," Prostate, Vol. 3, No. 1, 1982, pp. 73-80. doi:10.1002/pros.2990030110

[6] P. Humphrey, "The Prostate Gland, Silverberg's Principals and Practice of Surgical Pathology and Cytopathology," Lippincott Williams \& Wilkins, New York, 2009, pp. 1791-1822.

[7] D. Dawam, A. H. Rafindadi and G. D. Kalayi, "Benign Prostatic Hyperplasia and Prostate Carcinoma in Native Africans," BJU International, Vol. 85, No. 9, 2000, pp. 1074-1077. doi:10.1046/j.1464-410x.2000.00677.x

[8] A. Billis, "Prostatic Atrophy: Clinicopathological Significance," BJU International, Vol. 36, No. 4, 2010, pp. 401-409. doi:10.1590/S1677-55382010000400003

[9] A. Billis, "Prostatic Atrophy: An Autopsy Study of a Histologic Mimic of Adenocarcinoma," Modern Pathology, Vol. 11, No. 1, 1998, pp. 47-54.

[10] C. E. Ejike and L. U. Ezeanyika, "Prevalence of Chronic Prostatitis Symptoms in a Randomly Surveyed Adult Population of Urban-Community-Dwelling Nigerian Males," International Journal of Urology, Vol. 15, No. 4, 2008, pp. 340-343. doi:10.1111/j.1442-2042.2008.02003.x

[11] J. Mehlhorn, "Prostatitis from the Morphologic Viewpoint-An Autopsy Analysis," Zeitschrift Urologie Nephrologie, Vol. 80, No. 5, 1987, pp. 253-258. 
[12] E. B. Attah, "Nonspecific Inflammatory Lesions of the Prostate. Spectrum and Patterns," International Surgery, Vol. 60, No. 3, 1975, pp. 158-162.

[13] K. Stamatiou, A. Alvizos, E. Agapitos and F. Sofras, "Incidence of Impalpable Carcinoma of the Prostate and of Non-Malignant and Precarcinomatous Lesions in Greek Male Population: An Autopsy Study," Prostate, Vol. 66, No. 12, 2006, pp. 1319-1328. doi:10.1002/pros.20339

[14] W. A. Sakr, A. Billis, P. Ekanem, T. Wilt and D. G. Bostwick, "Epidemiology of High-Grade Prostatic Intraepithelial Neoplasia," Scandinavian Journal of Urology and Nephrology, Vol. 205, 2000, pp. 11-18. doi: $10.1080 / 003655900750169275$

[15] F. F. Angwafo III, A. Zaher, R. Befidi-Mengue, A. Wonkam, I. Takougang, I. Powell, et al., "The National Health Survey Team of The National Epidemiology Board of Cameroon: High-grade Intra-Epithelial Neoplasia and Prostate Cancer in Dibombari, Cameroon," Prostate Cancer and Prostatic Diseases, Vol. 6, No. 1, 2003, pp. 34-38.

[16] M. A. Salami, B. Etukakpan and E. O. Olapade-Olaopa, "Update on Prostate Cancer in Black Men," Journal of Men's Health, Vol. 4, No. 4, 2007, pp. 456-463.

[17] B. Vainer, B. G. Toft, K. E. Olsen, G. K. Jacobseen and N. Marcussen, "Handling of Radical Prostatectomy Specimens: Total or Partial Embedding?" Histopathology, Vol. 58, No. 2, 2011, pp. 211-216. doi:10.1111/j.1365-2559.2011.03741.x

[18] A. R. Rich, "On the Frequency of Occurrence of Occult Carcinoma of the Prostate," International Journal of Epidemiology, Vol. 36, No. 2, 2007, pp. 274-277. doi:10.1093/ije/dym050

[19] F. F. Angwafo III, A. Zaher, R. Befidi-Mengue, A. Wonkam, I. Takougang, I. Powell, et al., "The National Health Survey Team of The National Epidemiology Board of Cameroon: High-Grade Intra-Epithelial Neoplasia and Prostate Cancer in Dibombari, Cameroon," Prostate Cancer and Prostatic Diseases, Vol. 6, No. 1, 2003, pp. 34-38.

[20] J. Adolfsson, "Commentary: On the Incidence of Histological Prostate Cancer and the Probable Diagnosis of Cases with Tumours Too Small to Produce Symptoms or to Attract Attention on Physical Examination-The Findings of Dr Arnold Rice Rich," International Journal of Epidemiology, Vol. 36, No. 2, 2007, pp. 285-257. doi:10.1093/ije/dym053

[21] G. Soos, I. Tsakiris, J. Szanto, C. Turzo, P. G. Haas and B. Dezso, "The Prevalence of Prostate Carcinoma and Its Precursor in Hungary: An Autopsy Study," European Urology, Vol. 48 No. 5, 2005, pp. 739-744. doi:10.1016/i.eururo.2005.08.010

[22] M. Gelfand, C. M. Ross, D. M. Blair, W. M. Castle and M. C. Weber, "Schistosomiasis of the Male Pelvic Organs. Severity of Infection as Determined by Digestion of Tissue and Histologic Methods in 300 Cadavers," American Journal of Tropical Medicine and Hygiene, Vol. 19, No. 5, 1970, pp. 779-784.

[23] S. J. Berry, D. S. Coffey, P. C. Walsh, et al., "The Development of Human Prostatic Hyperplasia with Age," Journal of Urology, Vol. 132, No. 3, 1984, pp. 474-479.
[24] R. Alexis and J. Domingo, "Schistosomiasis and Adenocarcinoma of Prostate. A Morphologic Study," Human Pathology, Vol. 17 No. 7, 1986, pp. 757-760. doi:10.1016/S0046-8177(86)80188-5

[25] L. M. Franks, "Latent Carcinoma of the Prostate," The Journal of Pathology and Bacteriology, Vol. 68, No. 2, 1954, pp. 603-616. doi:10.1002/path.1700680233

[26] W. A. Sakr, G. P. Haas and B. F. Cassin, "The Frequency of Carcinoma and Intraepithelial Neoplasia of the Prostate in Young Male Patients," Journal of Urology, Vol. 150, No. 2, 1993, pp. 379-385.

[27] W. A. Sakr, D. J. Grignon, G. P. Haas, K. L. Schomer, L. K. Heibrun, B. J. Cassin, et al., "Epidemiology of High Grade Prostatic Intraepithelial Neoplasia," PathologyResearch and Practice, Vol. 191, No. 9, 1995, pp. 838841. doi:10.1016/S0344-0338(11)80965-9

[28] F. T. Odedina, T. O. Akinremi, F. Chinegwundoh, R. Roberts, D. Yu, R. R. Reams, et al., "Prostate Cancer Disparities in Black Men of African Descent: A Comparative Literature Review of Prostate Cancer Burden among Black Men in the United States, Caribbean, United Kingdom, and West Africa," Infectious Agents and Cancer, Vol. 4, Suppl. 1, 2009, p. S2. doi:10.1186/1750-9378-4-S1-S2

[29] J. O. Ogunbiyi and O. B. Shittu, "Increased incidence of prostate cancer in Nigerians," Journal of the National Medical Association, Vol. 91 No. 3, 1999, pp. 159-164.

[30] T. A. Badmus, A. R. Adesunkanmi, B. M. Yusuf, G. O. Oseni, A. K. Eziyi, T. I. Bakare, et al., "Burden of Prostate Cancer in South-Western Nigeria," Urology, Vol. 76 No. 2, 2010, pp. 412-416. doi:10.1016/j.urology.2010.03.020

[31] G. A. Magoha, "Epidemiological and Clinical Aspects of Incidental Carcinoma of the Prostate in Africans: Experience at the Lagos University Teaching Hospital, Lagos and the Kenyatta National Hospital, Nairobi," East African Medical Journal, Vol. 72, No. 5, 1995, pp. 283-287.

[32] A. Z. Mohammed, S. U. Alhassan, S. T. Edino and O. Ochicha, "Histopathological Review of Prostatic Diseases in Kano, Nigeria," Nigerian Postgraduate Medical Journal, Vol. 10, No. 1, 2003, pp. 1-5.

[33] P. S. Gill, I. S. D. Roberts, L. Browning, R. Periera, A. Y. Warren, F. C. Hamdy and C. Verrill, "The Handling and Sampling of Radical Prostatectomy Specimens for Reporting and Research: The Oxford Approach," Journal of Clinical Pathology, Vol. 65, No. 12, 2012, pp. 1057-1061. doi:10.1136/jclinpath-2012-200923

[34] D. G. Bostwick and I. Meiers, "Prostate," In: N. Weidner, R. J. Cote, S. Suster and L. M. Weiss, Eds., Modern Surgical Pathology, Saunders Elsevier, Philadelphia, 2009, pp. 1121-1158. doi:10.1016/B978-1-4160-3966-2.00032-1

[35] O. O. Erinomo, "Histopathological Pattern of Prostatic Lesions in Lagos University Teaching Hospital (LUTH) Lagos: A 12-Month Prospective Autopsy Study (January to December 2009)," Dissertation, The National Postgraduate Medical College of Nigeria, Lagos, 2010.

[36] G. M. Edington, I. Nwabuebo and T. A. Junaid, "The Pathology of Schistosomiasis in Ibadan, Nigeria with 
Special Reference to the Appendix, Brain, Pancreas and Genital Organs," Transactions of the Royal Society of Tropical Medicine \& Hygiene, Vol. 69, No. 1, 1975, pp. 153-156. doi:10.1016/0035-9203(75)90027-9

[37] C. C. Anunobi, A. A. Banjo, F. B. Abdulkareem, A. O. Daramola, O. R. Akinde and S. O. Elesha, "Bladder Cancer in Lagos: A 15 Year Histopathologic Review," The Nigerian Postgraduate Medical Journal, Vol. 17, No. 1, 2010, pp. 40-44.

[38] R. J. Cohen, S. G. Edger and K. Cooker, "Schistosomiasis and Prostate Cancer," Pathology, Vol. 27, No. 2, 1995, pp. 115-116. doi:10.1080/00313029500169682

[39] C. J. Godec, I. Grunberger and G. A. Carr, "Simultaneous Presence of Schistosomiasis and Advanced Cancer in Prostate," Urology, Vol. 39, No. 6, 1992, pp. 547-549. doi:10.1016/0090-4295(92)90014-N

[40] T. K. F. Ma and J. R. Srigley, "Adenocarcinoma of Prostate and Schistosomiasis: A Rare Association," Histopathology, Vol. 27, No. 2, 1995, pp. 187-189. doi:10.1111/j.1365-2559.1995.tb00028.x

[41] A. A. Cabasilio-de-Oliveira, E. F. Simon, W. A. EyerSilva, "Concomitant Prostatic Schistosomiasis and Adenocarcinoma: Case Report and Review," Brazilian Journal of Infectious Diseases, Vol. 6, No. 1, 2002, pp. 45-49.
[42] F. M. E. Wagenlehner, J. E. Elkahwaji, F. Algaba, T. Bierklund-Johansen, K. G. Naber, R. Hartung, et al., "The Role of Inflammation and Infection in the Pathogenesis of Prostate Carcinoma," BJU International, Vol. 100, No. 4, 2007, pp. 733-737. doi:10.1111/j.1464-410X.2007.07091.x

[43] G. S. Palpattu, S. Sutcliffe, P. J. Bastian, E. A. Platz, A. M. De Marzo, W. B. Isaacs, et al., "Prostate Carcinogenesis and Inflammation: Emerging Insights," Carcinogenesis, Vol. 26, No. 7, 2004, pp. 1170-1181. doi:10.1093/carcin/bgh317

[44] A. Holsken, M. Gebhardt, M. Buchfelder, R. Fahlbush, I. Blumcke and R. Buselei, "EGFR Signaling Regulates Tumor Cell Migration in Craniopharyngiomas," Clinical Cancer Research, Vol. 17, 2011, pp. 4367-4377. doi:10.1158/1078-0432.CCR-10-2811

[45] J. Edwards, P. Traynor, A. F. Munro, C. F. Pirret, B. Dunne and J. M. S. Bartlett, "The Role of HER1-HER4 and EGFRvIII in Hormone Refractory Prostate Cancer," Clinical Cancer Research, Vol. 12, 2006, pp. 123-130. doi:10.1158/1078-0432.CCR-05-1445

[46] R. A. Moore, "The Evolution and Involution of the Prostate Gland," American Journal of Pathology, Vol. 12, 1936, pp. 599-624. 